\title{
Transradial approach for vertebral artery stenting
}

\author{
Damian Maciejewski ${ }^{1}$, tukasz Tekielii ${ }^{1}$, Anna Kabłak-Ziembicka ${ }^{1}$, Piotr Paluszek², Mariusz Trystuła ${ }^{2}$, \\ Magdalena Wójcik-Pędziwiatr ${ }^{3}$, Roman Machnik², Piotr Pieniążek ${ }^{1}$ \\ ${ }^{1}$ Department of Interventional Cardiology, Institute of Cardiology, Medical College, Jagiellonian University, John Paul II Hospital, Krakow, \\ Poland \\ 2Department of Vascular Surgery and Endovascular Interventions, Medical College, Jagiellonian University, John Paul II Hospital, Krakow, \\ Poland \\ ${ }^{3}$ Department of Neurology, John Paul II Hospital, Krakow, Poland
}

Postep Kardiol Inter 2015; 11, 1 (39): 32-36

DOI: $10.5114 / p w k i .2015 .49182$

\begin{abstract}
A bstract
Introductuion: Symptomatic severe vertebral artery (VA) stenosis may be treated safely with stent supported angioplasty via femoral access. There is limited clinical data on transradial approach for VA angioplasty in case of peripheral artery disease.

Aim: To evaluate the safety and efficacy of transradial angioplasty of symptomatic VA stenosis.

Material and methods: Fifteen patients (age $66 \pm 7.4$ years, 73\% men, with VA > 80\% stenosis, 11 right-side, all symptomatic from posterior circulation (history of stroke, TIA, or chronic ischaemia symptoms)) with peripheral artery disease (PAD) or unsuccessful attempt via femoral approach were scheduled for VA angioplasty by radial access. Clinical and duplex ultrasound (DUS) follow-up were performed before discharge and 1, 12, and 24 months after VA angioplasty.

Results: The technical success rate was $100 \%$. In all cases VA angioplasty was performed with the use of single balloon-mounted stent ( 9 bare metal stents, 6 drug-eluting stents). The mean NASCET VA stenosis was reduced from $85.3 \%$ to $5.3 \%(p<0.001)$. No periprocedural death, stroke, myocardial infarction, or transient ischaemic attack occurred. During 24-months follow-up, in 12 of 15 patients chronic ischaemia symptoms release was observed, and no new acute ischaemic neurological symptoms were diagnosed in all patients. One patient died 20 months after intervention from unknown causes. There was one symptomatic borderline VA in-stent stenosis 12 months after angioplasty.

Conclusions: Transradial VA stenting may be a very effective and safe procedure, and it may constitute an alternative to the femoral approach in patients with symptomatic VA stenosis.
\end{abstract}

Key words: vertebral artery stenting, radial approach, peripheral artery disease.

\section{Introduction}

Stroke remains a major cause of mortality and disability in adults. Approximately one quarter of ischaemic strokes are located in the posterior circulation [1, 2]. Atherosclerotic stenosis of the vertebral artery (VA) is a potential cause of vertebrobasilar ischaemia and may account for about $20 \%$ of posterior circulation strokes [3]. Ostium is the most frequent location of VA stenosis.

Vertebral artery stenting via transfemoral approach has been shown to be safe and effective in the periprocedural period as well as in long-term follow-up [4]. Transradial access recently received an IA recommendation as it was demonstrated to be the safest way to perform coronary territory interventions [5]. Moreover, it has been successfully applied also for carotid artery stenting $[6,7]$.
Thus, in patients with severe symptomatic VA stenosis with coexisting peripheral artery disease or unfavourable aortic arch/subclavian artery anatomy, transradial access might be a viable alternative to the transfemoral approach. Transradial coronary intervention experience may increase the chance for success in vertebral territory [8].

\section{Aim}

We report transradial VA angioplasty outcome in 15 patients with peripheral artery disease or unsuccessful attempt from femoral access.

\section{Material and methods}

Between Jan 2010 and Jul 2014, 15 patients with severe, symptomatic VA stenosis were included in study. Table I shows patient characteristics. All VA stenosis as well

\section{Corresponding author:}

Damian R. Maciejewski MD, Department of Interventional Cardiology, Institute of Cardiology, Medical College, Jagiellonian University, John Paul II Hospital, 80 Pradnicka St, 31-202 Krakow, Poland, phone: +48 609448 745, e-mail: damianmaciejewski@tlen.pl

Received: 17.12.2014, accepted: 8.01.2015. 
as aortic arch anatomy were demonstrated in computed tomographic angiography (Figure 1 A). Transfemoral access was not feasible due to peripheral artery disease (PAD) in $8(53 \%)$ patients and due to severe subclavian artery tortuosity in 7 (47\%) patients.

All patients underwent examination by the site neurologist. Chronic posterior circulation ischaemia (dizziness/unilateral limb weakness/dysarthria/blurred vision) were diagnosed in 15 (100\%) patients, recurrent drop attacks in 3 (20\%), and history of vertebrobasilar stroke/ transient ischaemic attack (TIA) in 2 (13\%) patients.

All patients had been treated protractedly with aspirin (75 mg per day), and prior to the procedure they received a $300 \mathrm{mg}$ loading dose of clopidogrel. After the VA angioplasty, the aspirin was maintained indefinitely, and $75 \mathrm{mg}$ per day of clopidogrel was continued for 1 month for bare metal stent and 12 months for drug-eluting stent. On the procedure day, the ipsilateral radial artery was punctured and a 6 Fr short arterial sheath was introduced. Heparin was given to achieve an activated coagulation time of 250 to 300 s. Over 0.035 inch $(0.889 \mathrm{~mm})$ diagnostic wire Judkins Right 4.0/6 Fr guiding catheter was advanced toward VA ostium (Figures 1 B, 2 A). In all patients 0.014 inch $(0.356 \mathrm{~mm})$ coronary guidewire was positioned at the distal segment of the vertebral artery. In 1 patient with soft plaque proximal vertebral stenosis FilterWire EZ (Boston Scientific) distal embolic protection device was used to minimise the risk of distal embolisation (Figure 2 B). Direct stenting was performed when possible. Before and after stent deployment, the degree of stenosis was evaluated by quantitative angiography (Figures 1 C-D, 2 C-D). Clinical and duplex ultrasound (DUS) control follow-up were performed before discharge and 1, 12, and 24 months after VA angioplasty. Significant in-stent stenosis criteria were peak systolic velocity $>120 \mathrm{~cm} / \mathrm{s}$ and/ or end-diastolic velocity $>40 \mathrm{~cm} / \mathrm{s}$ [9].

\section{Results}

Technical success defined as stent implantation with residual stenosis $<20 \%$, no significant dissection, and TIMI 3 flow was achieved in 15 (100\%) patients. In one patient asymptomatic stent edge dissection was observed and this did not require any additional intervention. In all cases VA angioplasty was performed with the use of a single balloon-mounted stent ( 9 bare metal stents, 6 drug-eluting stents). Direct stent implantation with 12-20 atm was performed in $9(60 \%)$ cases. At ostial location, stents were post-dilated proximally with 12-22 atm. The mean NASCET VA stenosis was reduced from $85.3 \%$ to $5.3 \%$ ( $p<0.001)$. Procedural data are summarised in Table II.

No periprocedural death, stroke, myocardial infarction, or transient ischaemic attack occurred. In 4 (26.6\%) patients with symptomatic coronary artery disease, coronary angiography was performed. Three (20\%) of these
Table I. Baseline clinical characteristics of patients $(n=15)$

\begin{tabular}{lc}
\hline Parameter & Results \\
\hline Age [years] & $66.4 \pm 7.4$ \\
\hline Gender, men & $11(73.3 \%)$ \\
\hline Vertigo & $15(100 \%)$ \\
\hline Recurrent syncope & $3(20 \%)$ \\
\hline Stroke/TIA & $2(13.3 \%)$ \\
\hline Hypertension & $15(100 \%)$ \\
\hline Diabetes mellitus & $5(33.3 \%)$ \\
\hline Dyslipidaemia & $14(93.3 \%)$ \\
\hline Coronary artery disease & $10(66.6 \%)$ \\
\hline Previous percutaneous intervention coronary & $8(53.3 \%)$ \\
\hline Previous myocardial infarction & $5(33.3 \%)$ \\
\hline History of coronary artery bypass grafting & $2(13.3 \%)$ \\
\hline Peripheral artery disease & $8(53.3 \%)$ \\
\hline Contralateral vertebral artery occlusion & $4(26.6 \%)$ \\
\hline Concurrent carotid disease & $4(26.6 \%)$ \\
\hline Concurrent subclavian disease & $2(13.3 \%)$ \\
\hline Concurrent brachiocephalicus truncus disease & $2(13.3 \%)$ \\
\hline Prior CVA/TIA* & $7(46.6 \%)$ \\
\hline${ }^{*}$ Cerebrovascular accident/transient ischaemic attack. &
\end{tabular}

patients underwent successful percutaneous coronary angioplasty 2-4 weeks after VA stenting.

During follow-up (range: 3-57 months, mean: 28.1 months) in 12 of 15 patients chronic ischaemia symptoms release were observed; no new acute ischaemic neurological symptoms were diagnosed in all patients. One patient died 20 months after intervention from unknown causes. Follow-up DUS velocities remained stable in all patients (mean peak systolic velocity of $1.26 \mathrm{~m} / \mathrm{s}$ $(0.5-2.3 \mathrm{~m} / \mathrm{s})$; end-diastolic velocity of $0.33 \mathrm{~m} / \mathrm{s}(0.13-$ $0.6 \mathrm{~m} / \mathrm{s}$ ). Two cases of DUS-revealed in-stent stenosis were not confirmed by computed tomography (CT) angiography. There was one symptomatic VA in-stent stenosis 12 months after angioplasty, revealed by DUS. As CT confirmed only borderline (50\%) in-stent stenosis, the patient was not qualified for intervention at that time.

\section{Discussion}

The transfemoral approach is commonly used for vertebral artery access [10]. However, aorto-iliac disease or unfavourable aortic arch/subclavian artery anatomy can make the procedure difficult or even impossible. Operators experienced in transradial access in coronary interventions may use it also for aortic arch arteries angioplasty, including VA stenting. In fact, those two procedural techniques do not differ much and require a similar set of devices and skills. Transfemoral access VA stenting usually did not involve the use of a neuroprotection device [4]. However, in selected cases it might be useful for preventing intracranial embolisation during procedures $[11,12]$. In our series of cases, there was one high-risk 

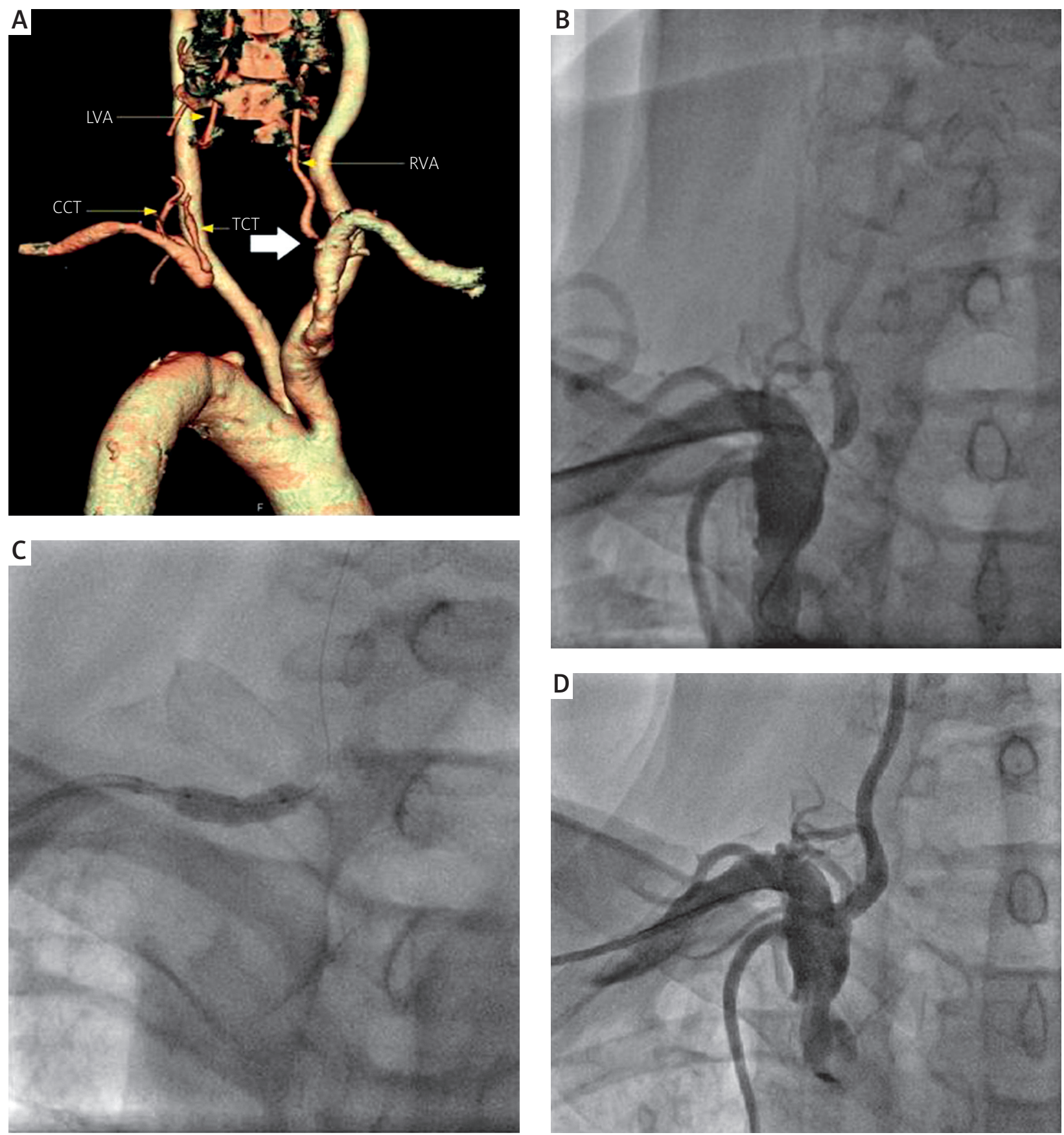

Figure 1. A - Left subclavian artery occlusion and right vertebral ostium stenosis (large arrow) diagnosed in CT angiography. B - Angiography confirming vertebral stenosis. C - Skylor $4.5 \mathrm{~mm} \times 13 \mathrm{~mm}$ post-dilatation. D - Final angiography showing optimal effect of VAS

RVA - right vertebral artery, LVA - left vertebral artery, CCT - costocervical trunk, TCT - thyrocervical trunk.

patient after ischaemic stroke with soft-plaque VA stenosis in whom we decided to apply distal embolic protection FilterWire EZ (Boston Scientific) with good result. No macroscopic embolic material was found in the system basket.

The well-known benefits of radial access are fewer vascular access complications and less major bleeding events, when compared with the femoral approach espe- cially in the older population and/or in patients receiving dual antiplatelet therapy - as in our series. Early mobilisation is another key advantage of the transradial technique, especially in older patients [13]. Duplex ultrasound plays an important role in the assessment of VA stenosis or in-stent stenosis; however, the demanding examination technique and interpretation may pose a serious problem for the operator. Therefore, VA DUS should be 

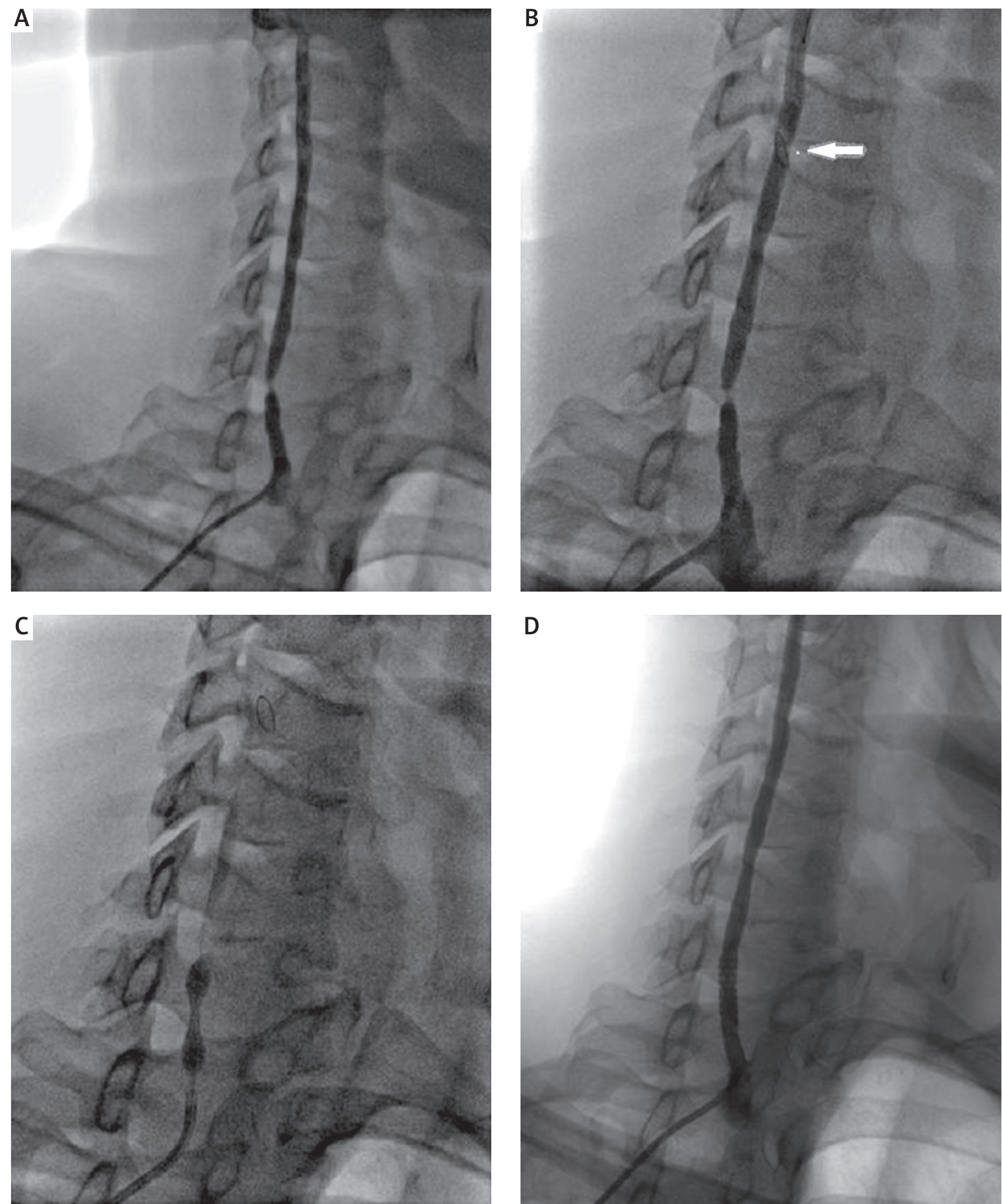

D

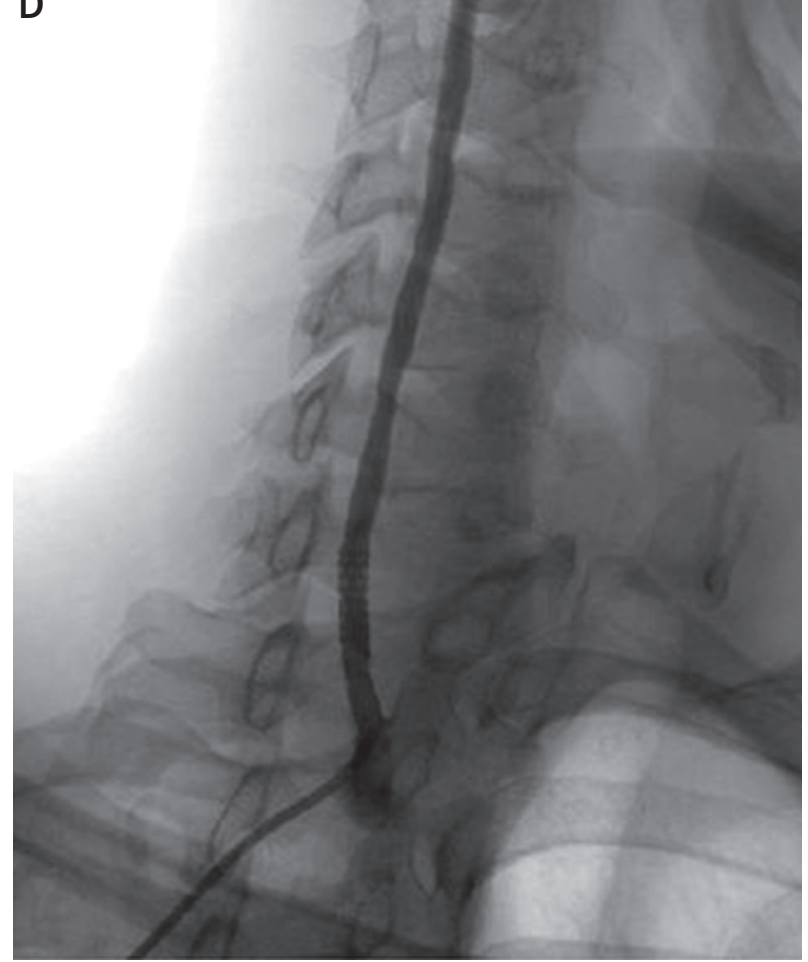

Figure 2. A - Selective angiography confirming right vertebral artery stenosis. B - FilterWire EZ distal embolic protection device (arrow). C - Balloon-expandable Nefro $5 \mathrm{~mm} \times 14 \mathrm{~mm}$ direct stenting. D - Final effect of transradial VAS

performed by experienced physicians. For example, tortuosity in the proximal part of VA or compensation of flow in case of contralateral VA occlusion may result in a significant increase in flow velocities. When in doubt,
$\mathrm{CT}$ angiography may be the best tool for precise artery stenosis degree evaluation. Computed tomography angiography also demonstrates high accuracy for diagnosis of VA in-stent stenosis [14]. 
Table II. Procedural data

\begin{tabular}{lc} 
Parameter & Results \\
\hline Left vertebral & $4(26.6 \%)$ \\
\hline Right vertebral & $11(73.3 \%)$ \\
\hline Balloon-expandable baremetal stent & $9(60 \%)$ \\
\hline Balloon-expandable drug-eluting stent & $6(40 \%)$ \\
\hline Stent diameter [mm] & $2.75-5.5$ \\
\hline Stent length [mm] & $6-19$ \\
\hline Direct stenting & $9(60 \%)$ \\
\hline Angiographic stenosis evaluation [\%]: & $86.4 \pm 8.7$ \\
\hline Pre-intervention & $5.3 \pm 6.4$
\end{tabular}

\section{Conclusions}

Our data shows that transradial VA stenting may be a very effective and safe procedure, and it may constitute an alternative to the femoral approach in patients with symptomatic VA stenosis. This refers especially to patients with PAD or with unfavourable aortic arch/subclavian artery anatomy.

\section{Conflict of interest}

The authors declare no conflict of interest.

\section{References}

1. Bamford J, Sandercock P, Dennis M, et al. Classification and natural history of clinically identifiable subtypes of cerebral infarction. Lancet 1991; 337: 1521-6.

2. Bogousslavsky J, van Melle G, Regli F. The Lausanne Stroke Registry: analysis of 1,000 consecutive patients with first stroke. Stroke 1988; 19: 1083-92.

3. Wityk RJ, Chang HM, Rosengart A, et al. Proximal extracranial vertebral artery disease in the New England Medical Center Posterior Circulation Registry. Arch Neurol 1998; 55: 470-8.

4. Paluszek P, Pieniążek P, Musiałek P, et al. Symptomatic vertebral artery stenting with use of bare metal and drug elitings stents. Postep Kardiol Inter 2009; 5: 1-6.

5. Hamon M, Pristipino C, Di Mario C, et al. Consensus document on the radial approach in percutaneous cardiovascular interventions: position paper by the European Association of Percutaneous Cardiovascular Interventions and Working Groups on Acute Cardiac Care and Thrombosis of the European Society of Cardiology. Eurolntervention 2013; 8 online publish-ahead-of-print January 2013.

6. Maciejewski D, Pieniążek P, Tekieli Ł, et al. Transradial approach for carotid artery stenting in a patient with severe peripheral artery disease. Postep Kardiol Inter 2014; 10: 47-9.

7. Ruzsa Z, Nemes B, Pinter L, et al. A randomized comparison of transradial and transfemoral approach for carotid artery stenting: RADCAR (RADial access for CARotid artery stenting) study. Eurolntervention 2014; 10: 381-91.

8. Lorenzoni R, Roffi M. Transradial access for peripheral and cerebrovascular interventions. J Invasive Cardiol 2013; 25: 529-36.

9. Kabłak-Ziembicka A, Przewłocki T, Pieniążek P, et al. Detection of atherosclerotic lesions in aortic arch arteries with Doppler ultrasound examination. Postep Kardiol Inter 2007; 3: 43-52.
10. Jenkins JS, Patel SN, White CJ, et al. Endovascular stenting for vertebral artery stenosis. J Am Coll Cardiol 2010; 55: 538-42.

11. Iwata T, Mori T, Tajiri H, Nakazaki M. Successful stenting by combination technique of reverse flow and downstream filtering for long chronic total occlusion of the cervical vertebral artery: technical case report. Neurosurgery 2009; 65: E378-9.

12. Pieniazek P, Musialek P, Motyl R, et al. Use of the parodi anti-emboli system and transient subclavian steal for cerebral protection during emergent vertebral artery recanalization. J Endovasc Ther 2004; 11: 511-6.

13. Bertrand OF, Belisle P, Joyal D, et al. Comparison of transradial and femoral approaches for percutaneous coronary interventions: a systematic review and hierarchical Bayesian meta-analysis. Am Heart J 2012; 163: 632-48.

14. Lee YJ, Lim YS, Lim HW, et al. Evaluation of in-stent restenosis after stent implantation in the vertebral artery ostium by multislice computed tomography angiography: factors affecting accurate diagnosis. Clin Neuroradiol 2014 Jun 12 [Epub ahead of print]. 